\title{
LA TRADICIÓN INDÍGENA FRENTE A LOS CAMBIOS LIBERALES
}

POR

MARGARITA MENEGUS

UNAM

El objetivo de este artículo es estudiar los cambios que sufrió la institución del cacicazgo en la región de la mixteca baja ubicada en el estado de Oaxaca a lo largo de los siglos XVIII y XIX. El trabajo se propone analizar los efectos que tuvo la revolución de independencia sobre el cacicazgo, tanto desde el punto de vista de la propiedad como de las relaciones sociales dentro del mismo. El artículo concluye que, a pesar de las propuestas de Cádiz y de las reformas que impulsaron los gobiernos liberales, el cacicazgo permaneció durante buena parte del siglo XIX sin muchos cambios. Fue el impuesto sobre la propiedad rústica a partir de la década de 1860 que motivó la venta de tierras pertenecientes a los cacicazgos entre sus antiguos terrazqueros.

Palabras Clave: Mixteca, comunidades indígenas, cacicazgo, propiedad.

Que en las Mistecas, especialmente en el distrito de Huajuapan, se presenta mucho ha un inconveniente para la tranquilidad de los pueblos y consiste ese notable mal en la presencia de una horda formal de llamados caciques, que hoy mas que nunca, agitan sus mas exageradas pretenciones al dominio de los terrenos en que existan las pueblos ${ }^{1}$.

\section{El CACICAZGo EN SU TRÁNSITO AL SIGLO XIX}

En 1823 se suprimió en México la propiedad vinculada a través de la figura del cacicazgo, o del mayorazgo. Unos años más tarde, el 2 de mayo

1 Carta de Narciso Francisco Paz, agosto de 1863. Archivo General del Estado de Oaxaca (en adelante AGEO). Repartos Leg. 12 exp. 4. 
de 1826, fueron derogados igualmente los títulos nobiliarios. No obstante, desde Cádiz, en 1811 se abolieron los señoríos. Aunque debemos precisar que se quitaron los señoríos jurisdiccionales y se mantuvieron los territoriales. Los señoríos jurisdiccionales en la Nueva España eran prácticamente inexistentes, salvo claro está el marquesado del Valle. Es decir, revirtieron al Estado los derechos exclusivos y privativos, que tenían los señoríos jurisdiccionales, además de la concesión de administrar la justicia ${ }^{2}$. En todo caso, debemos decir que las reformas de Cádiz modificaron poco la realidad novohispana, en cuanto a la propiedad, ya que no se afectó al señorío territorial o solariego, que en derecho es la figura más cercana a la institución del cacicazgo.

El proceso de desamortización de la propiedad corporativa es distinto, a la dinámica de desvinculación de la propiedad privilegiada. No obstante, ambos procesos son igualmente importantes para comprender el esfuerzo liberal por constituir la propiedad moderna en México. Con respecto al mayorazgo, Bartolomé Clavero dijo: «La desvinculación significa la transformación del derecho de propiedad, no necesariamente la enajenación de las propiedades $»^{3}$. Esta premisa se aplica igualmente al cacicazgo. Se pierde el vínculo, es decir, los privilegios que prohibían la venta de los bienes y la subdivisión de la propiedad entre los herederos, pero no se altera la titularidad de la propiedad. Es decir, sencillamente se vuelve propiedad privada sujeta a las leyes de herencia vigentes.

En este sentido, la región que ahora nos ocupa en este artículo corresponde a una zona que no es precisamente representativa de México. La mixteca, pero particularmente la mixteca baja es una región en donde predominó la institución del cacicazgo por encima de la estructura de las repúblicas de indios. Es decir, a diferencia de buena parte de la Nueva España en donde los pueblos indígenas fueron congregados y constituidos en repúblicas con gobierno propio y con tierras comunales propias, en la mixteca permanecieron los antiguos linajes prehispánicos quienes no sólo controlaban un territorio amplio, sino que también lo gobernaban.

Para comprender mejor la naturaleza de la propiedad de un cacicazgo en la mixteca hemos incluido un plano correspondiente al cacicazgo de los Villagómez. Como podrá observar el lector a simple vista se trata de un conjunto de territorios dispersos a lo largo de un amplísimo espacio geográfico. El cacicazgo de los Villagómez poseía tierras desde la mixteca poblana, Acatlan y Piastla, pasando por la mixteca baja y llegaba hasta Yanhuitlan en la Mixteca Alta.

2 Peset, 1982: 90-92.

3 Clavero, 1974: 413. 
No es un territorio continuo, sino disperso, salpicado. Así al disolverse los lazos que unían dicho cacicazgo, se iniciaron los conflictos con un sinnúmero de poblaciones que tradicionalmente habitaban dichas tierras. La transformación de la propiedad así como de las relaciones sociales, económicas y políticas de la región presupuso la disolución de las servidumbres impuestas a la población de terrazgueros asentados dentro de los distintos cacicazgos ${ }^{4}$.

\section{EL CACICAZGO DE HUAJUAPAN VILLAGOMEZ}

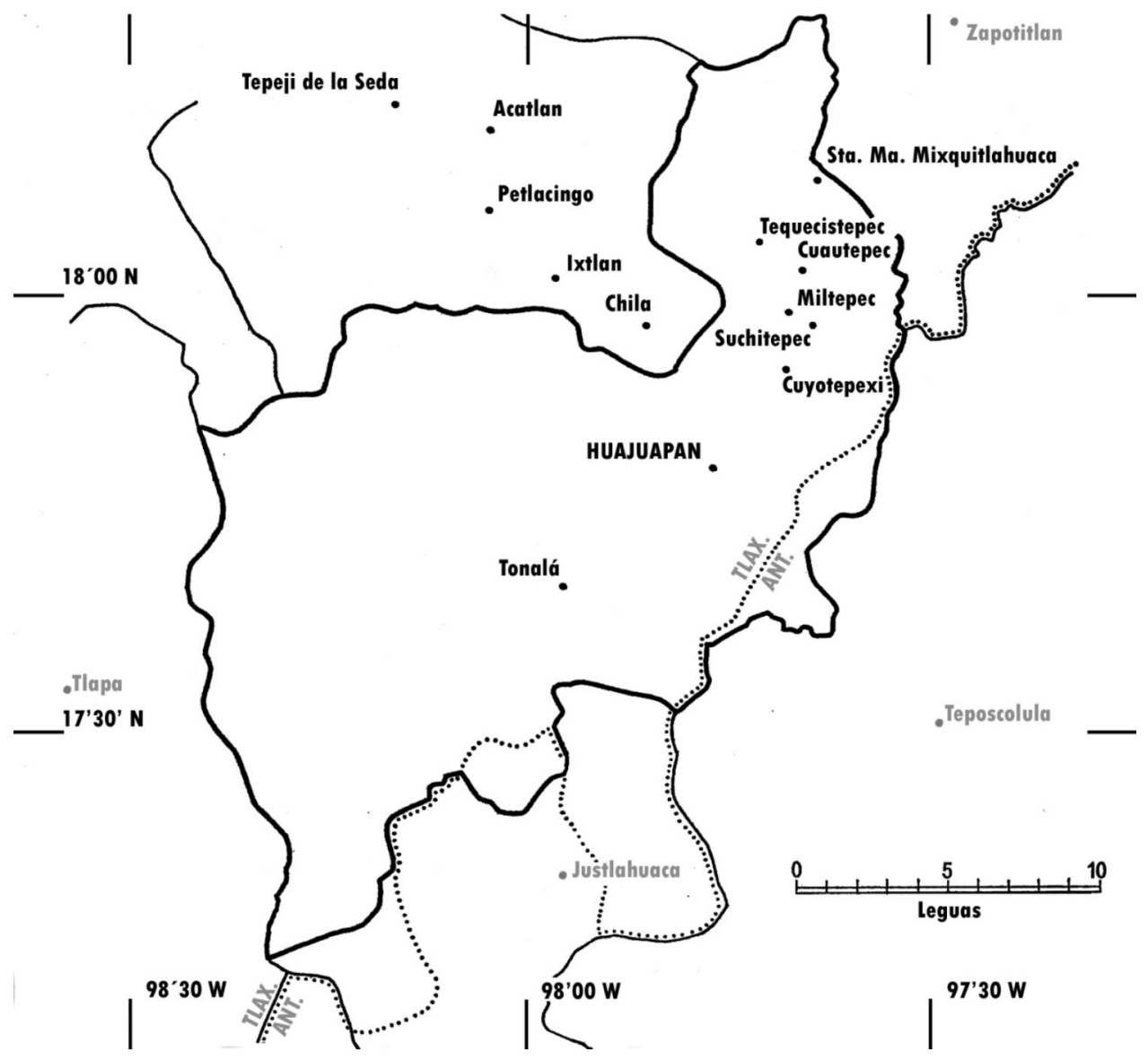

4 Para mayor información sobre la diversidad de cacicazgos en la Nueva España, veáse Menegus y Aguirre, 2005. 
Dicho lo anterior, este ensayo se propone estudiar la transformación y fin del cacicazgo colonial en la primera mitad del siglo XIX, desde la perspectiva de los mixtecos asentados tradicionalmente en tierras de los señores naturales. Dicho de otro modo, nos preguntamos qué significó para los antiguos terrazgueros la desaparición del cacicazgo y la introducción de la propiedad liberal.

Para el siglo XIX la historia agraria se ha enfocado mas al estudio de la desamortización de la propiedad eclesiástica o civil, dejando a un lado el tema que ahora nos proponemos abordar. La propiedad eclesiástica o la comunal presuponen un carácter colectivo de la titularidad del mismo, cosa que no sucede bajo el régimen del cacicazgo. El titular del cacicazgo es uno, aunque al igual que en el régimen del mayorazgo se compartían los beneficios o rentas con otros miembros de la familia. No obstante, en el cacicazgo existen derechos yuxtapuestos. Y es precisamente la yuxtaposición de derechos lo que hace del cacicazgo una institución única. Los terrazgueros asentados dentro del cacicazgo usufructuaban de una parte de las tierras mientras que el cacique mantenía la posesión directa del mismo. Sin embargo, la propiedad liberal no admite las yuxtaposiciones, sino únicamente la propiedad plena, y ésta debe descansar en manos de un solo titular. Dicho esto, los liberales buscaron terminar con la propiedad, en donde convergían dos dominios, el útil y el directo. De tal manera se suprimió el cacicazgo y también se disolvieron a lo largo del siglo XIX los censos enfitéuticos tan extendidos en la Nueva España en tierras señoriales.

Justamente en las páginas siguientes daremos cuenta de cómo evolucionaron algunos cacicazgos de Huajuapan en su tránsito hacia la modernidad. La región de Huajuapan se ubica en la mixteca baja en el actual estado de Oaxaca. Es una región semiárida que une a Puebla con el Valle Central de Oaxaca. Llama poderosamente la atención que en la documentación temprana del siglo XIX, después de la ley de 1823 que suprimió a la nobleza y a los mayorazgos, y en consecuencia a los cacicazgos, no encontramos en la documentación judicial consultada ninguna referencia a esta ley, y que inclusive se sigue hablando de caciques, cacicazgos y de vínculos. En un principio se comienza a introducir el concepto de ciudadano-cacique, posteriormente, se les denomina ex cacique, no obstante, me parece interesante subrayar la dificultad que demuestran las autoridades a lo largo del siglo XIX para despojarse del vocablo mismo. Por otra parte, sustituyen sin razón jurídica aparente el término de cacicazgo por el término quizás más discreto de vínculo o aparentemente menos ofensivo. En todo caso es un sinsentido jurídico.

Si bien podemos considerar que la ley por sí misma suprimió de facto la propiedad privilegiada, convirtiendo los bienes que integraban el cacicazgo en propiedad privada, lo cierto es que los caciques mantuvieron grandes exten- 
siones de tierras y continuaron arrendando las tierras a los pobladores asentados dentro de sus cacicazgos. Ciertamente el arrendamiento de las tierras del cacicazgo no presenta de suyo ningún problema para la propiedad liberal. Sin embargo, como veremos mas abajo, la población asentada dentro de los cacicazgos, reclamó sus derechos propios a una parte de esa propiedad. Por otra parte, los campesinos mixtecos encararon una lucha secular por hacerse de una propiedad propia. En el caso de la Mixteca, la institución del cacicazgo entró en crisis desde principios del siglo XVIII. Esta crisis se manifestó cuando varias poblaciones de terrazqueros (asentados en tierras del cacicazgo) buscaron independizarse de sus caciques fundando pueblos o repúblicas de indios independientes. Sin embargo, pocas poblaciones lograron liberarse de sus caciques.

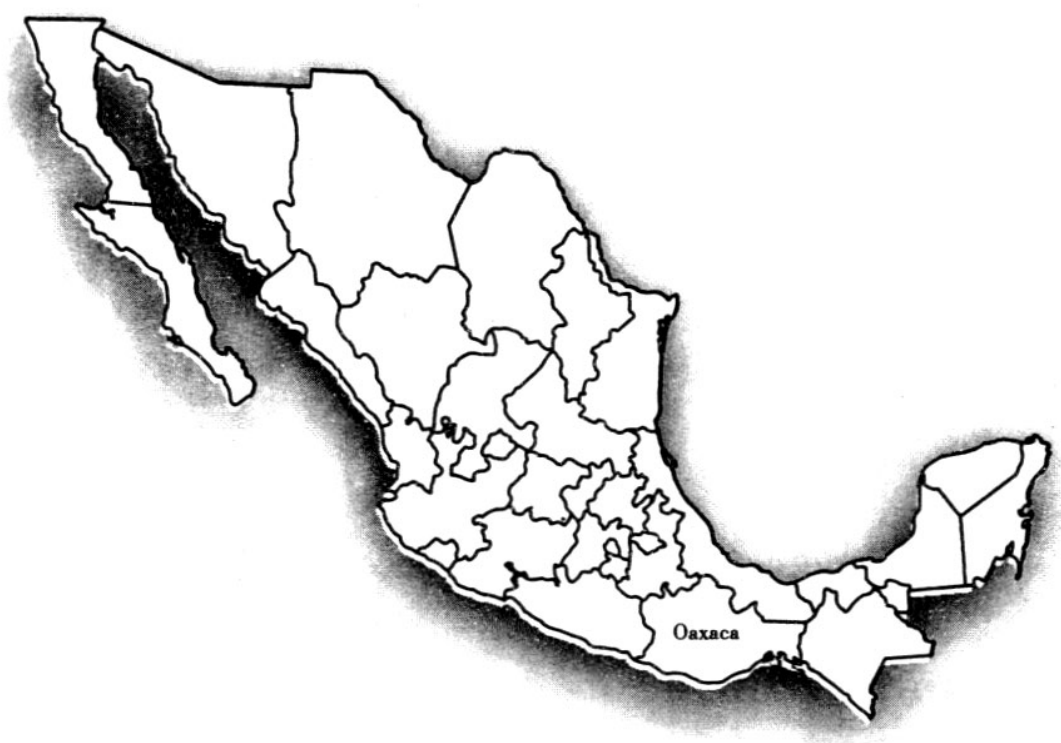

UBICACIÓN DEL ESTADO DE OAXACA

Para nuestro propósito también es menester, revisar los derechos diversos, a los cuales tenían acceso un cacique, los cuales no estaban explícitamente vinculados a la tierra, sino a las características más señoriales que conservaron algunos cacicazgos. Me refiero, por ejemplo, a los servicios personales o a los llamados terrazgos dados a los caciques, de manera regular o excepcional. Finalmente, en algunos de los cacicazgos de esta región, así como en otras zonas 
que hemos revisado, el cacique mantuvo un control sobre el gobierno de las repúblicas de indios. Es decir, habría que revisar y ver qué sucedió con los privilegios inherentes a su señorío, privilegios diversos que están más allá de la propiedad.

Si bien la ley Lerdo de 1856 nada tiene que ver con las tierras pertenecientes a los antiguos cacicazgos, ya que como he dicho tan sólo se desconoce el vínculo, es decir, el privilegio que mantenía unida la propiedad. Sin embargo, lo cierto es que el cacicazgo se ve afectado de manera indirecta al otorgarle al arrendatario o usufructuario de la tierra el derecho de compra de la tierra que trabaja. En este sentido veremos cómo los pueblos se acogen a ese derecho para comprar o no la tierra que ancestralmente usufructuaban convirtiéndose en pequeños propietarios. En otros casos compraron sus terrenos a través de sociedades mercantiles que les permitió mantener la unidad del territorio, bajo el régimen de la propiedad privada liberal.

Finalmente, veremos que la ley de 1823, ni la ley Lerdo afectaron sustancialmente la propiedad de los ex caciques, sino que la fragmentación de la propiedad antiguamente vinculada tuvo que esperar a que el Estado se consolidara y aplicará el impuesto predial, para incitar a la venta y fragmentación de esos

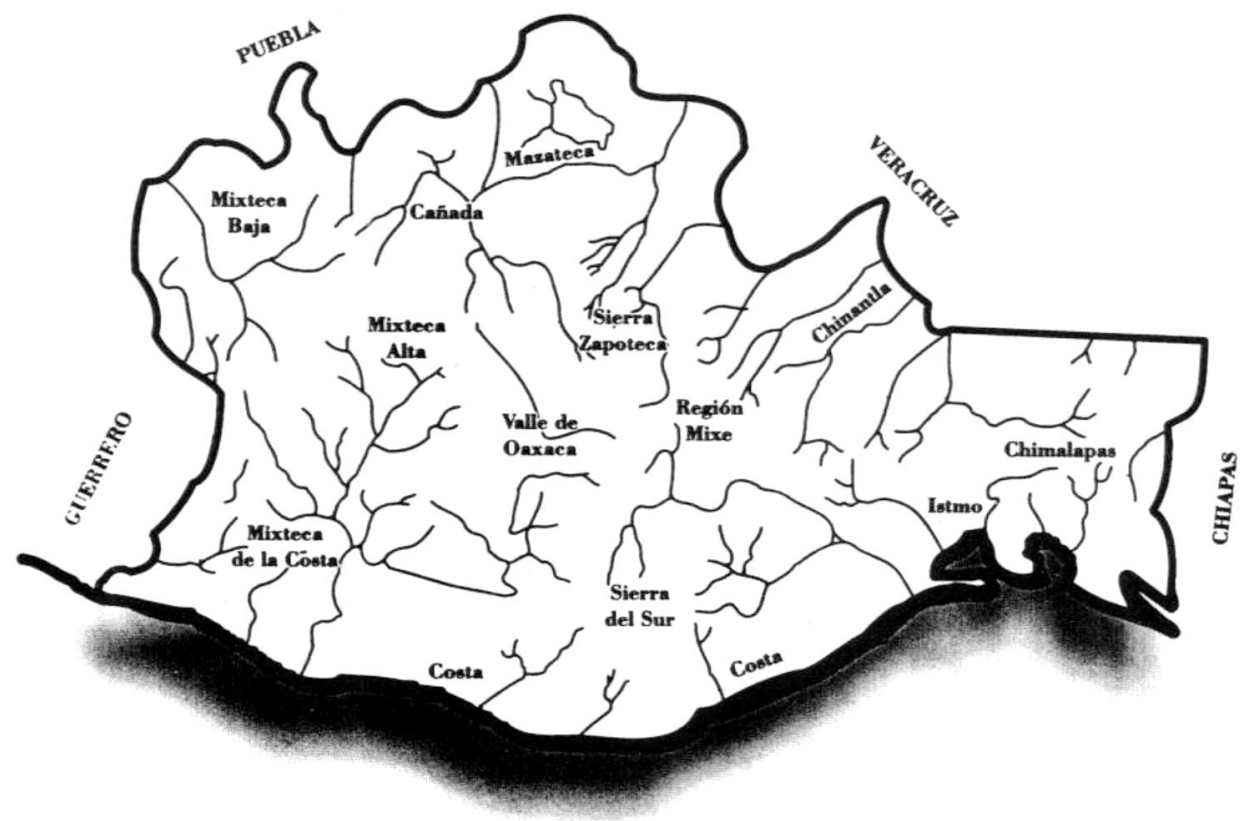

UBICACIÓN DE LAS REGIONES DE OAXACA 
enormes territorios. La historiografía frecuentemente olvida que la propiedad en el antiguo régimen no tributaba, y fueron los liberales, sobre todo a partir de los planteamientos de Adam Smith, quienes redefinieron la riqueza en función de la propiedad. De ahí que en la construcción del Estado moderno y de su nueva fiscalidad, la propiedad reformada es un elemento importantísimo.

\section{LOS EFECTOS DE LA INSURGENCIA EN LA PROPIEDAD}

El periodo insurgente afecta tímidamente la estructura agraria existente en la región de Huajuapan. Las proclamas de Morelos y de otros insurgentes cambiaron poco la vida de los pueblos de indios. Sin embargo, la inestabilidad política del momento influyó de manera indirecta. El mundo indígena en el siglo XVIII entra en crisis, y particularmente es en el cacicazgo en donde se agudiza esta situación durante el periodo de la insurgencia. La ruptura en cuanto a las relaciones tradicionales existentes entre el cacique y sus terrazqueros, más precisamente, me refiero a las relaciones de reciprocidad que caracterizaban esta relación en la época prehispánica se desquebrajaban lentamente. A lo largo del siglo XVI y XVII el cacicazgo sufrió un desgaste silencioso, pero constante, debido a múltiples razones. En vísperas de la Independencia la crisis que vive el cacicazgo se refleja por ejemplo, en los intentos realizados por los terrazqueros por constituirse en pueblos independientes, separándose de sus caciques, como ya hemos mencionado arriba. La real cédula que otorgaba a los pueblos indígenas derecho a solicitar la medición de las 600 varas a los cuatro vientos provocó a lo largo del siglo XVIII innumerables conflictos entre pueblos cabeceras y sus sujetos, así como entre caciques y sus terrazqueros.

A principios de 1812 el intendente de Oaxaca, avisado de las incursiones de los rebeldes en la región, prohibió que las personas comunes pudiesen andar a caballo y portar armas y se reserva dicho privilegio solamente para algunos. Al poco tiempo Morelos nombró a Manuel Trujado «Comandante para las Mixtecas», y por parte del rey fue nombrado don José María Regules Villasantes, natural de Santander y vecino del comercio de Nochixtlan, jefe de las fuerzas armadas en esa zona. Se enfrentaron ambos bandos en Yanhuitlan, en donde el jefe de los realistas mandó fusilar al gobernador indígena y a su alcalde por sospechar que eran simpatizantes de los rebeldes. Oaxaca ciudad fue tomada por los ejércitos de Morelos el 25 de noviembre de 1812. Hubo poca resistencia según nos dice Ana Carolina Ibarra, ya que Morelos rápidamente pactó con los criollos y con las corporaciones más significativas para establecer su gobierno. Morelos estuvo en Oaxaca hasta febrero de 1813 cuando salió 
rumbo a Acapulco. Durante su estancia en Oaxaca dictó varias providencias, en primer lugar: «que ningún europeo quedara en el gobierno que se aboliesen las jerigonzas de calidades como indio, mulato, mestizo tente en el aire etc., llamándolos a todos americanos, que como consecuencia de ello, nadie pagase tributo, los naturales fuesen dueños de sus tierras y rentas, y que prevaleciera la igualdad frente a los requerimientos de alcabalas $\mathrm{u}$ otras condiciones fiscales o comerciales ${ }^{5}$. Las disposiciones dictadas por Morelos carecían de originalidad, pues el virrey Francisco Xavier Venegas, el 26 de mayo de 1810, había ordenado suprimir el tributo en la Nueva España. El mismo documento determinó el repartimiento de tierras a los pueblos que tuviesen necesidad de ellas. Existe una relación casi indisoluble entre la propiedad y la reforma fiscal. La supresión del tributo y el reparto de tierras fueron confirmados por las Cortes de Cádiz. Con todo, la abolición del tributo personal que pagaban los indios tenía claras implicaciones políticas que apuntaban hacia una reestructuración de la sociedad novohispana. La idea de suprimir la división de la sociedad en dos repúblicas ya había sido propuesta años antes por Abad y Queipo en su famosa Representación de los Labradores. Este hecho por sí mismo introduce la idea de la igualdad política entre todos los miembros de la sociedad novohispana. Nadie pagaría ahora un impuesto personal, sino únicamente los tributos considerados reales o indirectos, como la alcabala. Así, a partir de 1811 , los indígenas estarían sujetos al pago de la alcabala, entre otras contribuciones indirectas. La modificación fiscal había sido ensayada años antes en 1791, sin embargo, como estudiamos en otra parte, finalmente se dio marcha atrás ${ }^{6}$. Es decir, es fácil advertir la relación entre el tributo y la propiedad y las reformas en materia de propiedad, como elementos necesarios para lograr una unificación fiscal.

Rodolfo Pastor, quien estudió este periodo para la Mixteca, es de la opinión de que los pueblos de indios se quejaron por igual de un bando, como del otro, pues ambos exigían contribuciones extraordinarias y provisiones para sostener la guerra. No obstante, menciona que los vecinos de San Miguel el Grande denunciaron la presencia de los rebeldes en la zona, a los realistas que estaban en el pueblo de Chalcatongo. El pueblo de la Magdalena Yodocono celebró la derrota de los insurgentes sacando en procesión el retrato de Felipe VII ${ }^{7}$. Con todo para 1816 se había logrado pacificar la región de la Mixteca.

5 Ávila, 2004. Ibarra, 2004: 255. Además, sobre la supresión del tributo en este periodo ver Menegus, 1998.

6 Menegus, 1998: 110- 130.

7 Pastor, 1987: 418. 
La inestabilidad política sin duda vino a contribuir a este proceso que hemos referido en otro trabajo como una ruptura en las relaciones tradicionales que se reproducían al interior del cacicazgo.

En 1818, por ejemplo, la cacica Reymunda Navarrete y Méndes, a través de su tutor y curador, por ser menor de edad, inició un litigio contra los naturales del pueblo de San Martín Zacatepec. El abogado de la cacica de Chila, afirmaba que los naturales de Zacatepec se habían introducido en las tierras de su cacicazgo usufructuándolas libremente a la sombra de la insurrección, desde enero de 1811 hasta 1818, cuando interpuso el litigio. Debido al aprovechamiento que habían hecho de las tierras del cacicazgo, el tutor José Amador exigió que los naturales del pueblo le pagaran a doña Reymunda Navarrete 25 pesos por cada año que las cultivaron. El gobernador de la república de Zacatepec, Martín Santiago contestó diciendo que el pueblo se resistía al pago pues consideraban que las tierras eran suyas ${ }^{8}$.

El pleito por tierras entre el cacicazgo de Chila y los del pueblo de Zacatepec, se había iniciado desde las últimas décadas del siglo XVIII, pero en 1804 la cacica obtuvo una resolución a su favor. Sin embargo, como nos dice su abogado:

Su carácter compasivo no le permitió dexar aquellos indios sin el subsidio del uso de algunas de las tierras por lo que continuaron sirviéndose de ellas, en calidad de prestadas por gracias... Es decir, debido a la generosidad de Reymunda los naturales de Zacatepec continuaron disfrutando de algunas parcelas.

Pero vino a interrumpir al ejercicio de sus defensas la insurrección de cuyo pretexto prevalecidos los naturales del predominado pueblo de San Martín han vuelto a introducirse en las tierras». Es decir, inspirados quizás en las proclamas de Morelos los indios volvieron a invadir las tierras del cacicazgo. En 1811, el 3 de septiembre, emitió José María Morelos, desde el Cuartel General Americano de Chilapa, un comunicado sobre la forma de persuadir a la gente del pueblo para incorporarse a las filas de la revolución. Ordenó quitar cuantas pensiones se podían, como los tributos y demás cargas que oprimían a los pueblos ${ }^{9}$. Unos meses antes se había pronunciado a favor de entregarle a los pueblos sus tierras y también se pronunció en contra del sistema de arrendamientos.

El tutor Amador remata su alegato diciendo: «Yo por razón de mis cargos, y por los preceptos de mi obligación no puedo ver con indiferencia al despotismo de estos naturales.... ${ }^{10}$.

En 1825 el cacique Ignacio Velasco y Mendoza, del pueblo de la Magdalena, jurisdicción de Huajuapan, inicia un litigio contra los naturales del pueblo

\footnotetext{
8 Archivo Histórico Judicial de Oaxaca Huajuapan Civil leg. 12 (en adelante AHJO).

9 Lemoine, 1991: 180.

10 AHJO. Huajuapan Civil Leg. 4.
} 
de Tequistepec por 22 sitios de tierra para ganado menor que intentaban apropiarse los naturales.

El alegato del abogado asienta lo siguiente:

Quando desde el principio que los españoles ocuparon injustamente este hermoso continente, no derrocaron a los caciques que poblaban la Misteca baja en donde esta situado Tequistepec.

Es decir, a pesar de la Independencia y de que se suprimió el 7 de agosto de 1823 el régimen del cacicazgo, el abogado considera que los caciques tenían un derecho legítimo cuyo origen precedía a la conquista hispana y defendió con el argumento de la antigüedad en derecho, el derecho de su cliente a su cacicazgo. Es decir, en todo caso la Independencia significaba liberarse del yugo de los españoles pero no de los caciques o señores naturales de la tierra.

Es decir, por lo menos en esta región que hemos analizado se transita al siglo XIX entre luces y sombras, se arrastran los problemas añejos hasta después de la independencia, y vemos como los caciques siguen disputando en los tribunales sus derechos ancestrales. Actúan sin reconocer que el cacicazgo fue suprimido. O más bien reinterpretaron la historia aludiendo a un derecho originario de los señores naturales.

El único pueblo, del que tenemos noticia que fue beneficiado concretamente por las fuerzas insurgentes fue el de San Juan Cutilo. Los testigos declararon lo siguiente:

que desde el tiempo del señor General León se les dan por gracia los terrenos que ocupa el pueblo por un pequeño reconocimiento porque el pueblo carece en lo Absoluto de terrenos propios». Además afirma que todas las tierras colindantes pertenecieron al señor Lara ${ }^{11}$. Es decir, a un cacique.

En suma, debemos tomar con pinzas las proclamas de los insurgentes, ya que rara vez se aplicaron, por un lado, y por otro, si se aplicaron, frecuentemente fueron revocados al poco tiempo. Sin embargo, se respira un ambiente propicio a disolver las diferencias étnicas marcadas principalmente por el tributo, pero también por la relación de vasallaje entre los naturales y sus señores.

11 AGEO. Repartos y Adjudicaciones leg. 12, exp. 8 f. 54. 


\section{LA YUXTAPOSICIÓN DE DERECHOS O LA NATURALEZA DE LA PROPIEDAD EN EL CACICAZGO}

Una característica fundamental de la propiedad del antiguo régimen es la yuxtaposición de derechos. Es decir, cuando la propiedad no es plena y cuando el ejercicio al derecho está limitado por un derecho que pertenece a otro tercero. Justamente en esta concepción de la yuxtaposición de derechos podemos ubicar los derechos inherentes al cacicazgo, en donde el titular tiene limitado su propiedad, por los derechos de usufructo que tenían los maceguales o terrazqueros pertenecientes al cacicazgo. En este punto me parece necesario hacer una pequeña desviación, para poder comprender mejor a mi juicio el problema que presenta la yuxtaposición de derechos. El cacicazgo originalmente conllevaba derechos señoriales. Es decir, mas allá de los derechos jurisdiccionales confirmados a los caciques, ya fuesen éstos de carácter administrativo o territoriales, también le fueron otorgados derechos como el servicio personal, o doméstico, e incluso el derecho a recibir un tributo y con ello el reconocimiento de un vasallaje y dependencia personal de los campesinos asentados dentro del cacicazgo. Este fenómeno, como veremos a continuación, se conservó durante buena parte del siglo XIX, en regiones como Huajuapan, en donde el cacicazgo predominó como estructura que definía todas las relaciones sociales, económicas y políticas.

Este fenómeno fue claramente expuesto en una carta redactada por la república de Acaquisapa y firmada por el escribano local Juan Anastasio, y los ciudadanos Tomás Martín e Ignacio Martínez. Los vecinos alegaron su derecho a una parte de la propiedad del cacicazgo de la siguiente manera:

No podemos negar que los presentes, ny nuestros antepasados, fueron y somos unos feudatarios de aquellos casiques, primero por la suma ignorancia, de que adoleciamos, y lo segundo por el rigor con que se nos tratava, pero nunca como arrendatarios, que quisa no hubieramos sido tan sacrificados, sino por un conbenio que se introdujo y después se volbio costumbre, de ayudar el pueblo con su dinero para defender las tierras, y de este modo y sin que a los caciques les costara nada se hacían dueños de las tierras.

Es muy interesante observar cómo el pueblo de Acaquisapa no reclama sus derechos a la tierra reivindicando su condición de arrendatarios, sino que alega un derecho ancestral. Como miembros de una casa señorial fueron «feudatarios» de los caciques pero nunca «arrendatarios». Y por esa condición defendieron sus tierras, las tierras del cacicazgo con su propio dinero y esfuerzo. Su derecho nace del «convenio» establecido entre los maceguales y su cacique, en donde se comprende la unidad del cacicazgo y en todo caso en esa propiedad vemos cómo se expresa la yuxtaposición de derechos. 
Por eso en el siguiente párrafo argumentan que ellos tienen tanto derecho a la propiedad como el cacique.

Lejos señor jues de que senos grabara como se pretende, debían vernos eternamente reconocidos, por que como llebamos dicho, al pueblo le deven ese benéfico de nombrarse dueños de tierras, luego el mismo grado debemos tener nosotros los verdaderos dueños, porque a espensas de nuestro dinero los hemos puesto en pocesión. A el efecto y por las noticias de nuestros mayores, hallándose la desendencia de los caciques mui miserables, y ausente, tomó la vos el pueblo, y se le dio pocesción el año de 1634 restituidos aquellos, los becinos que veillan estos como a Dioces, los recibieron, y continuaron en sus servicios personales, contribullendo con mas exceso, para la posesión que tomaron el año de $1767 \mathrm{y}$ asi sucesivamente por los años de 1768, 1770, 1777, 1791, 1818, 1826. Saliendo del volcillo de los vecinos sumas considerados de pesos para mantenerlos en pocecion de aquellas tierras sin mas recompensa que lo poco que disfrutan de ellos, por ser notoriamente malos, y que mirándolo a buen servicio los tenemos recompensados ${ }^{12}$.

Es decir, como integrantes de un cacicazgo sentían la obligación compartida con el cacique de defender sus tierras. Se veían ellos y su cacique como una unidad en donde ambas partes tenían derechos, aunque diferenciados.

Ha la presente nos hallamos reducidos a casi solo el circuito del pueblo, porque los colindantes se han introducido en lo mas, y como que la actual pocedora no trata de defenderlas tenemos la necesidad de pagarles aquellos para no ser molestados... cuando efectivamente fuéramos arrendatarios, no podríamos pagar, ni a uno, ni a otro, para no exponer nuestro dinero, pero mucho menos no habiéndolo sido; por estos sólidos motibos venimos en suplicar a la notoria justificación de v., se sirba notificar a la Xímenez no nos perturbe de manera laguna; por nos dexe vivir en quietud como hasta aquí; apercibiéndola que por su causa se quieren salir barrios vecinos, con culla falta se entorpece la... ${ }^{13}$

En suma, los vecinos de este cacicazgo vivían sobre tierras del mismo, y como tales se reconocen a sí mismos como propietarios o copropietarios. Cada vez que había un conflicto de límites salían en defensa del cacicazgo y costeaban los gastos del pleito, indicando con ello su carácter de propietarios.

\section{LA PERMANENCIA DE LOS DERECHOS SEÑORIALES DEL CACICAZGO}

La población asentada sobre tierras que habían pertenecido a un cacicazgo, por lo menos en la primera mitad del siglo XIX, continuaron pagando un terrazgo y dando servicios personales al cacique. Por ejemplo, en 1832 tenemos una lista de los «ciudadanos» que disfrutaban de tierras en Acaquisapa perte-

\footnotetext{
12 AHJO. Huajuapan Civil 1832, exp. 13.

13 AHJO. Huajuapan Civil 1832, exp. 13.
} 
necientes a la ex cacica doña María Josefa Ximénez ${ }^{14}$. En ese documento se registra a cada individuo junto con las siembras que realizan y los ganados que poseen. Todos tenían una milpa de maíz, además siembran fríjol, chile y tomate. Algunos poseían yuntas, otros, ganado mayor o menor. Generalmente todos tenían pitallas y acostumbraban: "contribuir a sus caciques cada año con una cavesa de ganado y un peso de plata ${ }^{15}$. No obstante, en esa década de 1830 algunos pueblos intentaron dejar de pagar los arrendamientos y terrazgos a los caciques, éste fue el caso de algunos de los naturales que disfrutaban tierras del cacicazgo de doña María Josefa Ximénez. La misma situación la enfrentó el cacique de Chasumba, quien interpuso un recurso contra varios terrazqueros que se habían resistido a pagar la renta de los terrenos que laboraban. El cacique hace notar que: «hace cuatro años que están deviendo el arriendo y terrazgo de los terrenos que disfrutan». Lo importante aquí de nuevo es la exigencia no de la renta, sino del terrazgo consistente en un pago adicional de una cabeza de ganado y un peso anualmente ${ }^{16}$.

La Independencia y el liberalismo no lograron imponerse en esta región, pues en 1832 el cacique de Chichilahuaca, y de San Andrés Acachina, y don Juan de la Cruz Mendoza solicitaron a la autoridad correspondiente: «se sirva renovarles la posesión en que se hallan de inmemorial tiempo» ${ }^{17}$. Los caciques ganaron sus litigios, no obstante, en boca de José María Benavides, en una carta al señor juez de primera instancia en representación del pueblo de Acaquisapa dijo:

No podrá negarse esta verdad, ni tampoco mis podatarios han querido salir del servilismo en que los tienen acostumbrados por su desgracia los ex caciques, pues estos señores en lo general abusando de la humildad y (de la) ninguna ilustración de los indígenas, aún los tienen bajo la férula en que vivían con nuestros antiguos opresores $^{18}$.

En esta región el hecho de que el régimen de cacicazgos fuesen la forma predominante de tenencia de la tierra obligó a los campesinos, a raíz de la ley Lerdo, a constituirse en sociedades mercantiles para adquirir tierra laborable. Así por ejemplo, los vecinos del pueblo de Cuyotepeji se constituyeron en sociedad mercantil para adquirir en 1869 tierras que habían pertenecido al caci-

14 Doña María Ximénez muere en 1828, y fue cacica de Acaquisapa. Estuvo casada con Venancio de la Rosa.

15 AHJO. Huajuapan Civil, leg. 6.

16 Idem. Año 1832, exp. 22.

17 Idem. Año 1832, exp. 25.

18 Idem, leg. 8, exp. 2. 
cazgo de los Villagómez ${ }^{19}$. En este proceso se revelan elementos de la relación tradicional entre el cacique y los maceguales asentados en el cacicazgo.

El pueblo estaba fundado sobre terrenos del finado cacique don Mariano Francisco Villagómez. La relación entre el cacique y los maceguales, como ya hemos explicado, en el siglo XVIII se volvió una relación contractual en muchos casos en otros no. Todos los terrenos que sembraban para atender sus necesidades lo hacían mediante contrato de arrendamiento y pagaban al dueño del cacicazgo una cantidad anual de más de cien pesos por arrendamiento de los sitios de las casas que les servían de habitación. Sin embargo, los pobladores además de pagar la renta de la tierra debían sembrar y cosechar las parcelas de cultivo del cacique. Asimismo tenían la obligación todos los moradores de Cuyotepeqi de hacer todas las labores consiguientes a la cosecha hasta que quedaba la semilla en trojes. Por otra parte, cuando alguno de los hijos del cacique se casaba, o había cualquier otra fiesta, los naturales tenían la obligación de proporcionarle gallinas, tortillas, pavos y demás servicios.

Muerto el cacique don Mariano Francisco Villagómez la misma situación continuó con su sucesor, don Andrés Villagómez. Claramente si bien eran terrazquerros en la época colonial siguieron usufructuando tierras del cacicazgo en el siglo XIX pagando una renta por las mismas parcelas, generalmente en servicios y no en monetario. Sin embargo, lo que llama poderosamente la atención es que a lo largo de la primera mitad del siglo XIX no se hayan abolido los servicios personales, que daba tradicionalmente el pueblo en reconocimiento al cacique.

Deseando todos los vecinos de nuestro pueblo, emanciparnos de esta clase de vasallaje, resolvimos comprarle a el cacique unas porciones de terreno suficiente de cubrir sus necesidades, y para no hacer un contrato contrario a la ley de 25 de junio de $1856, \ldots$ supuesto que esta próvido las comunidades civiles, adquirir, poseer, y administrar bienes raíces, resolvimos formar una sociedad que sin que tuviera el carácter de tal comunidad civil ${ }^{20}$.

Compraron un total de cinco sitios de ganado mayor en nueve mil pesos. A la firma del contrato entregaron dos mil 900 pesos quedando el resto distribuido en distintos pagos.

Es decir, que hasta que se volvieron propietarios dejaron de ser vasallos del cacique.

19 AHJO, leg. 12, exp. 6.

20 AHJO, leg. 12, exp. 6. 


\section{EL OCASO DEL CACICAZGO}

\section{El impuesto a la propiedad}

La propiedad del antiguo régimen no tributaba. Por ello, consideramos que el impuesto sobre la propiedad en el México independiente es quizás la razón más importante por sí sola que condujo al desmembramiento de las grandes propiedades indígenas. Adam Smith propuso gravar la tierra, debido a que era un bien con una renta intrínseca ${ }^{21}$.

Lamentablemente la historiografía mexicana carece aún de estudios suficientes sobre el impuesto a la propiedad en el siglo XIX que nos permita tener un panorama general de la situación. Ello se debe, en parte, a la dificultad que presupone para el historiador atajar el tema de la fiscalidad en un periodo tan convulso como fue el siglo XIX mexicano. Pero quizás más importante es el hecho de que la estructura de propiedad en México era muy diversa. La propiedad comunal en manos de los pueblos o la propiedad corporativa en manos de la Iglesia fueron las que primero atacaron los liberales. No obstante, la disolución principalmente de la propiedad comunal indígena fue un largo y dilatado proceso que llevo casi todo el siglo transformar. Con todo, al poco tiempo se produjo la Revolución Mexicana, la cual de nuevo replanteó el problema de la propiedad comunal e inventó la propiedad ejidal. Habiendo dicho esto resulta claro que el tema de los cacicazgos extinguidos tuvo menos relevancia frente a las otras propiedades, visto desde la perspectiva nacional. No obstante, como ya hemos mencionado para esta región de Oaxaca en particular constituye la forma dominante de la propiedad durante todo el periodo colonial.

Hace algunos años, Paolo Riguzzi analizó parcialmente la situación para el estado de México. Para el caso del estado de México sabemos que la contribución predial fue decretada en 1861, sin embargo, no empieza a ser cobrada regularmente sino hasta 1868-1869. En un principio se cobraba una cuota de 7 al millar sobre el valor de las fincas rústicas y urbanas, y posteriormente fue en aumento hasta alcanzar 10 al millar en $1879^{22}$. El impuesto predial aumentó en cuanto a su representatividad en la composición de los ingresos estatales al disminuir el impuesto de la capitación. Según este mismo autor, en la década de 1870 se intentó elaborar un catastro, sin embargo, fue un fracaso, y afirma que dicho instrumento de vital importancia para gravar la propiedad, no se logró sino hasta 1923. En Oaxaca en cambio se elabora el primer catastro en 1914.

\footnotetext{
21 Roll, 1967: 157.

22 Riguzzi, 1994: 229.
} 
Para el caso del estado de Oaxaca, Edgar Mendoza ha incursionado un poco en este tema. En Oaxaca los impuestos sobre fincas rústicas y urbanas fueron introducidos durante el gobierno centralista. En 1839 el pueblo de San Miguel Tequixtepec, elaboró una lista de los contribuyentes y se consigna que pagaban desde un tlaco, media cuartilla, hasta nueve reales cada vecino.

Según la información que nos proporciona Edgar Mendoza se gravaba tanto el terreno, como el ganado. En el pueblo de la Concepción Buenavista el valor de las fincas rústicas en 1842 variaban de 4 pesos hasta 114. El número total de propietarios era de 54. Sólo 6 individuos concentraban el 30\% del valor de la propiedad. En cambio, 34 propietarios tenían fincas que oscilaban entre los 4 y los 40 pesos.

En 1846 sólo nueve individuos pagaban la contribución, es decir, los más acaudalados; Alrededor de 3 reales anuales, mientras que los demás sencillamente no tributaban.

En el pueblo de Tepelmeme sucedía algo igual. Sólo los más ricos del pueblo pagaban la contribución.

Con el retorno del régimen federalista la contribución sobre fincas rústicas no desapareció. En 1847 Benito Juárez, gobernador de Oaxaca, decretó que la contribución de tres al millar impuesta sobre el valor de las fincas rústicas y urbanas continuará conforme estaba ya establecido ${ }^{23}$.

No obstante los esfuerzos difuminados de los políticos decimonónicos, el impuesto a la propiedad tuvo poca importancia desde el punto de vista de los recaudadores, sobre todo si consideramos que ni si quiera para el periodo había un catastro. Sin embargo, para los ex caciques el tema era muy relevante debido a la extensión y dispersión de sus propiedades. Así lo dejan sentir numerosos ex caciques de la región que se quejan desde la década de 1860 contra dicho gravamen.

En 1860 el cacique José María Bautista se quejaba del impuesto que gravaba su propiedad. El cacique, en sus propias palabras, dice que estaba muy apremiado por el pago de las contribuciones de tres al millar y el uno por ciento que se le asignaron por los terrenos de su cacicazgo según leyes que al efecto habían sido expedidas por el superior gobierno. Y argumenta que no teniendo recursos para pagarlos se veía en la necesidad de vender una parte de los terrenos, en este caso precisamente los terrenos que tenía arrendados a los del pueblo de Chazmaba. Dice que esos terrenos los usaban los vecinos de Chazmaba para pastar en común sus ganados y fija su precio en la cantidad de 2.500 pesos $^{24}$.

23 Mendoza, 2004.

24 AHJO. Huajuapan Civil, leg. 37. 
Otro caso fue el de don Calisto Ramírez, quien fue sucesor de la ex cacica su madre doña Isidora Feria y Mendoza, decidió vender unos terrenos de su cacicazgo debido a que como él mismo dice:

careciendo de recursos para satisfacer las contribuciones que debo al superior gobierno por el vínculo de Santa Catarina Yntandu que se compone del terreno que este pueblo a disfrutado a nombre mía hasta hoy he determinado venderlo toda la vez que no hay embarazo para ello puesto que esto en quieta y pacífica pocesión de dicho terreno y no se perjudica ningún tercero por tanto, me es conveniente proponer la venta primera a los inquilinos de aquel pueblo, que en renta han poseído ..... sic a fin de que digan si cada uno para si, o en sociedad me compran o renuncian la preferencia que puedan tener en este caso $^{25}$.

En 1864, Leandro Alvarado, sucesor del cacicazgo de Cahilualco, igualmente dice enajenar algunos de sus bienes y afirma que:

debiendo vender al mejor postor, el terreno en que está situado el pueblo de San Gerónimo Nuchisa, cuya vecinos han sido los antiguos arrendatarios de el, para saldar el pago de contribuciones que se han recargado en cantidades de consideración, en la Administración de rentas de esa Villa, de he merecer de V. Se sirva hacer que previa citación comparesca ante la presencia judicial de V la República del expresado pueblo de Nulusa y dándoles a saber e contenido de mi ocurso, ... si el vecindario tiene o no posibilidades de comprarme, para contratar con ellos en el primer caso o en el contrario para hacerlo libremente con cualquiera persona que se me precente... ${ }^{26}$.

Son numerosos los casos de los caciques que comienzan a vender su patrimonio ancestral en la década de 1860 alegando que los impuestos eran demasiado onerosos, sin embargo estos pocos ejemplos nos sirven para ilustrar que la puntilla de la institución que sobrevivió cuatro siglos vio su fin a raíz del impuesto sobre la propiedad. La institución había sobrevivido los embates de las poblaciones indígenas que intentaron desde fines del XVII y a lo largo del XVIII sustraerse de sus caciques sin mucho éxito. Los caciques de la mixteca lograron a diferencia de cualquier otro lugar de la Nueva España preservar e incrementar su patrimonio, no obstante, la institución vio su fin en esta región ante la amenaza que significo el impuesto a la propiedad.

Así, ante la necesidad económica, la ex cacica doña Petra Aya buscó venderles a sus antiguos terrazqueros las tierras, como fue el caso para tantos otros caciques. Pero ella curiosamente les advirtió de que si no la compraban las tierras que cultivaban ya tenía arreglado con el Ministerio del Interior para que mediante la inmigración de extranjeros se repoblaran esas tierras que antiguamente habían sido de su patrimonio secular.

\footnotetext{
25 Idem, leg. 39.

26 Idem, leg. 42.
} 


\section{A MODO DE CONCLUSIÓN}

Con este ejercicio hemos querido sugerir que la disolución de las relaciones económicas y sociales en el campo mexicano cambiaron lentamente desde el siglo XVIII hasta finales del siglo XIX. En regiones como Huajuapan, en donde el cacicazgo era la forma predominante de la estructura de la propiedad, la transición hacia el liberalismo se produjo de una manera muy distinta a como se dio este proceso de modernización en regiones en donde predominaba la estructura de pueblos con propiedad corporativa. Los cacicazgos entraron en crisis desde el siglo de las luces, principalmente al proponerse los terrazqueros separarse de sus caciques y formar pueblos independientes con derecho a la propiedad y con un gobierno propio. Sin embargo, la Corona en muchas ocasiones en esta región de Oaxaca de la Mixteca favoreció a los caciques confirmando sus derechos y en pocas ocasiones permitió la separación de terrazqueros de sus caciques para constituirse en pueblos. El siglo XIX heredó las tensiones preindependentistas y los caciques resistieron los embates de la modernidad. El predominio del cacicazgo en esta región de Huajuapan llevó a una transición hacia el siglo liberal muy peculiar en donde la población campesina pasó de ser terrazqueros a miembros de una sociedad mercantil en el mejor de los casos. En otros casos, fueron despojados del usufructo de sus tierras al no poder comprar las tierras pertenecientes a los antiguos cacicazgos. Solamente los naturales que lograron en el transcurso del siglo XVIII establecerse como un pueblo con tierra y gobierno propio, utilizando la legislación correspondiente a las 600 varas, pudieron adjudicarse la propiedad que usufructuaban a raíz de la ley Lerdo de 1856. Finalmente, quiero insistir en la importancia de las cargas y pensiones que siguieron gravando a los campesinos asentados en la propiedad de los caciques durante buena parte del siglo XIX, con el propósito de subrayar que la propiedad expresa también relaciones sociales y económicas.

\section{BIBLIOGRAFÍA}

Ávila, Alfredo, «Entregar Oaxaca a los insurgentes. La frustrada conspiración de 1811», Ana Carolina Ibarra (coord.), La Independencia en el sur de México, México, UNAM, 2004.

Clavero, Bartolomé, Mayorazgo. Propiedad feudal en Castilla (1369-1620), México, Siglo XXI, 1974.

Jáuregui, Luis et al., Las finanzas públicas en los siglos XVIII-XIX, México, Instituto José María Luis Mora, 1998.

Lemoine, Ernesto, Morelos, Su vida revolucionaria a través de sus escritos y de otros testimonios de la época, México, UNAM, 1991. 
Mendoza, Edgar, De sujetos a municipios: resistencia y adaptación de los pueblos chocholtecos a las políticas liberales del siglo XIX, 1825-1889, Tesis de doctorado, El Colegio de México, 2004.

Menegus, Margarita, «Tributo o alcabala. Los indios y el fisco (siglos XVI al XIX). Una encrucijada fiscal», Luis Jáuregui et al., Las finanzas públicas en los siglos XVIII-XIX, México, Instituto José María Luis Mora, 1998: 110-130.

Menegus, Margarita y Aguirre, Rodolfo, El cacicazgo en Nueva España y Filipinas, México, UNAM y Plaza y Valdés, 2005.

Pastor, Rodolfo, Campesinos y reformas: La Mixteca, 1700-1856, México, El Colegio de México, 1987.

Peset, Mariano, Dos ensayos sobre la historia de la propiedad de la tierra, Madrid, 1982.

Riguzzi, Paolo, «El camino hacia la modernidad: la hacienda publica del Estado de México, 1870-1923», Carlos Marichal et al., El primer siglo de la Hacienda Pública del Estado de México 1824-1923. Historia de la Hacienda Pública del Estado de México, vol. I, México, El Colegio Mexiquense y el Gobierno del Estado de México, 1994.

Roll, Eric, Historia de las doctrinas económicas, México, FCE, 1967.

Fecha de recepción: 15-1-2007

Enviado a modificar: 11-2-2007

Enviado conforme a las normas: 21-1-2008

\section{INDIGENOUS TRADITIONS IN THE FACE OF LIBERAL POLICIES}

This article examines the development of the institution of cacicazgo in the Mixteca region of Oaxaca during the eighteenth and nineteenth centuries. Its main aim is to demonstrate the effects of the Revolution of Independence on the structures of property ownership and social relationships that lay at the heart of the cacicazgo system. It concludes that cacicazgo prevailed well into the nineteenth century despite the reforms issued both at Cadiz and later on by liberal governments. It suggests that the structure of land ownership in the Mixteca Baja changed as a result of the imposition of taxation on private property, which rendered the extensive property holdings on which the cacicazgo was based overly burdensome, thus obliging caciques to sell off their extensive properties to their erstwhile tenants.

KEY WORDS: Mixteca, indigenous communities, cacicazgo, property. 